\title{
Shielding and Activation Analyses for BTF Facility at SNS
}

\author{
Irina Popova ${ }^{1, *}$ and Franz X. Gallmeier ${ }^{1}$ \\ ${ }^{1}$ ORNL, PO box 2008, MS 6466, Oak Ridge, TN 37831-6474, USA
}

\begin{abstract}
The beam test facility (BTF), which simulates front end of the Spallation Neutron Source (SNS), has been built at the SNS, and is preparing for commissioning. The BTF has been assembled and will operate in one of service buildings at the site. The $2.5 \mathrm{MeV}$ proton beam, produced in the facility, will be stopped in the beam dump. In order to support BTF project from radiation protection site, neutronics simulations and activation analyses were performed to evaluate the necessary shielding around the facility and radionuclide inventory of the beam stop.
\end{abstract}

\section{Introduction}

The beam test facility (BTF) will be a copy of the accelerator front end of the Spallation Neutron Source (SNS) facility and will be used for test and development of new front-end equipment, for conducting research in accelerator physics (in a further build-out) for SNS second target station moderator development (tests). The BTF is assembled and will be operating in the radio frequency (RF) on-site annex building. Negatively charged hydrogen ions $\left(\mathrm{H}^{-}\right)$, generated at the ion source, will be accelerated to $2.5 \mathrm{MeV}$. The facility is capable of producing one-ms-long pulses at $60 \mathrm{~Hz}$ repetition rate with up to $50 \mathrm{~mA}$ peak current. This beam will be safely terminated in the beam stop.

In order to support the BTF project from radiation protection point of view, neutronics simulations and activation analyses were performed to develop shielding around the beam stop, evaluate dose rates in case of an accident and to evaluate the radionuclide inventory at the facility end-of-life for decommissioning.

The challenge of the analyses was to consider the low energy charges particles reaction physics to fit the calculations into our routine transport and activation methods as practiced for the much higher energy spallation environment.

\section{BTF layout}

BTF is a "room sized accelerator", which is located in a technical support building on SNS site. BTF consists of a $65 \mathrm{keV} \mathrm{H}^{-}$ion source, a Low Energy Beam Transport (LEBT), a $2.5 \mathrm{MeV}$ Radio Frequency Quadrupole Accelerator (RFQ), a Medium Energy Beam Transport (MEBT) diagnostic systems, a high power beam stop and support systems. A V shaped beam stop is located at the end of MEBT, which is being re-used from SNS commissioning. The water-cooled beam stop is made from TZM, which is an alloy of $0.50 \%$ titanium, $0.08 \%$ zirconium and $0.02 \%$ carbon with the balance molybdenum, with density of $10.2 \mathrm{~g} / \mathrm{cc}$, and it is watercooled. The beam stop from SNS Frontend commissioning was re-used in this setup. A radiation level of $300 \mathrm{mrem} /$ hour at $30 \mathrm{~cm}$ distance from the surface is expected at full beam power, according to measurements performed during the commissioning, which requires radiation shielding to be installed.

For the neutronics analyses of dose rates in the vicinity of the BTF beam stop and to design appropriate shielding, a very simple model of the beam stop in MCNPX language was developed. This model was used later for activation calculations as well.

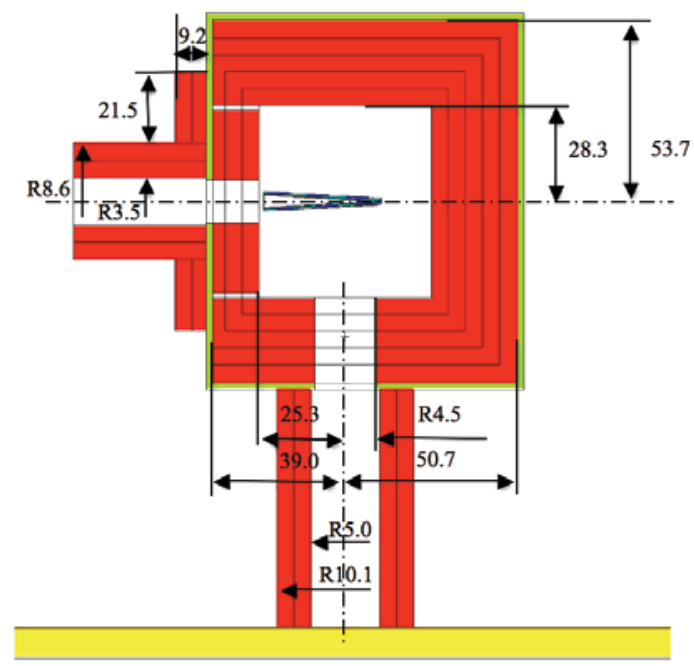

Figure 1. Vertical cross section of the beam stop shielding configuration, dimensions are in $\mathrm{cm}$.

The model for the analyses is presented in Figure 1 with the water-cooled beam stop, is $\mathrm{V}$ shaped assembly in the middle of Figure 1 and is shown in greater detail in Figure 2. The calculational model of the beam stop consists from 4 cells - inner cell, outer cell, end cell and water between inner and outer cells. The layers of TZM,

\footnotetext{
* Corresponding author: popovai@ornl.gov
} 
where the protons impact, is too small to see, and located on the inner surface of the water layer.

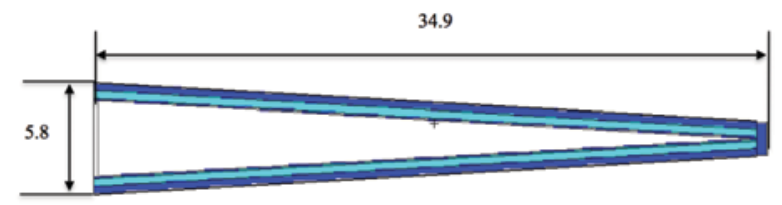

Figure 2. Vertical cross section of the beam stop, dimensions are in $\mathrm{cm}$.

The $\mathrm{H}^{-}$beam is delivered by the beam pipe from the left side of the figure and intercepts the beam stop. The beam stop is surrounded by a shielding configuration consisting of $5 \%$ borated polyethylene, red color, enclosed in $1.9 \mathrm{~cm}$ steel, green color, resting on a concrete floor, yellow color, under the beam stop shielding assembly.

There are two penetrations at the beam stop shielding - one is on the upstream edge of the shielding for the beam pipe and the second is on the bottom portion of the shielding, under the beam stop for wiring and piping. It was shown in the analyses that the dose rates were high in penetration vicinity and, in order to reduce dose rates, additional borated polyethylene shielding was suggested around both penetrations.

\section{Methods for the analyses and source terms}

\subsection{Dose rates evaluations}

Shielding analyses at SNS are routinely performed using the Monte Carlo transport code MCNPX [1]. Evaluated proton reaction cross sections are sparse, and physics models not applicable for energy range in interest, which is up to $2.5 \mathrm{MeV}$. A hand estimate of secondary neutrons and gammas yield resulting from protons reactions with TZM beam stop was performed.

The negatively charged hydrogen ions $\left(\mathrm{H}^{-}\right)$, generated at the ion source, are accelerated in the BTF assembly up to $2.5 \mathrm{MeV}$ before they interact with the beam stop material. The source is a $\mathrm{H}^{-}$beam corresponding to the SNS accelerator full beam at $50 \mathrm{~mA}, 1 \mathrm{~ms}, 60 \mathrm{~Hz}$, The averaged beam current is $3 \mathrm{~mA}$, which is converted into number of $\mathrm{H}^{-}$per second -1.87 . $10^{16} \mathrm{H}^{-} / \mathrm{s}$.

The simplified model for the hand estimation considers a massive material structure (TZM) hit by the $2.5 \mathrm{MeV}$ proton beam. For simplicity, all secondary particles are considered to be distributed isotropically.

The reaction rate for producing neutrons or gammas from proton interactions is:

$$
R=\Phi^{p} \sigma N V
$$

where $\sigma$ is average cross section for reaction $(\mathrm{p}, \mathrm{n})$ or $(\mathrm{p}, \mathrm{g}), N$ is the nuclear concentration of the target isotope (nucleus/barn*cm), $V$ is the target volume and $\Phi^{p}$ is the proton flux. Proton cross sections for $(\mathrm{p}, \mathrm{n})$ and $(\mathrm{p}, \mathrm{g})$ reactions are taken from Experimental Nuclear Reaction Data (EXFOR) [2]. The proton flux may be determined as the number of protons per second $(n)$ per $\mathrm{cm}^{3}(V)$ of material multiplied by the track length through the material or stopping length $(d)$.

$$
\Phi^{p=} n d / V
$$

Then the reaction rate will be:

$$
R=n d \sigma N
$$

Because the proton energy is low $(2.5 \mathrm{MeV})$ the neutrons and gammas will be born very close to the point where the proton beam hits the material. Hence, the produced neutrons or gammas may be considered as a point source. Using the number of produced neutron or gamma reaction rates, the fluxes have been calculated by dividing the reaction rate by the area of the sphere with radii $(r)$ corresponding to the distance from the material.

Finally dose rates are calculated by multiplying the calculated fluxes by flux to dose conversion factors. In order to be conservative, for neutron interactions the flux to dose conversion factor is taken for $2.5 \mathrm{MeV}$ both neutrons and gammas. The non-attenuated neutron dose rate at $30 \mathrm{~cm}$ for full beam is expected to be approximately $324 \mathrm{mrem} / \mathrm{h}$ according to the results of the analyses, which are shown at Table 1 and compare well to the measurements during the commissioning $(300 \mathrm{mrem} / \mathrm{h})$.

\begin{tabular}{|c|c|c|c|}
\hline $\begin{array}{l}\text { Isotope and } \\
\text { reaction }\end{array}$ & $\begin{array}{c}\text { Cross } \\
\text { section, } \\
\text { mb }\end{array}$ & $\begin{array}{c}\text { Reaction rate } \\
\text { at full beam, } \\
\text { particle/s }\end{array}$ & $\begin{array}{c}\text { Dose Rate at } \\
30 \mathrm{~cm}, \\
\mathrm{mrem} / \mathrm{hr}\end{array}$ \\
\hline $\operatorname{Mo} 92(\mathrm{p}, \mathrm{g})$ & $2.50 \mathrm{E}-02$ & $1.16 \mathrm{E}+07$ & $2.24 \mathrm{E}+00$ \\
\hline Mo94(p,g) & $5.00 \mathrm{E}-02$ & $1.44 \mathrm{E}+07$ & $2.80 \mathrm{E}+00$ \\
\hline Mo95(p,g) & $6.00 \mathrm{E}-02$ & $2.98 \mathrm{E}$ & $5.77 \mathrm{E}+00$ \\
\hline $\mathrm{Zr94}(\mathrm{p}, \mathrm{n})$ & 0.11 & $5.04 \mathrm{E}+04$ & $6.24 \mathrm{E}-01$ \\
\hline $\operatorname{Ti} 49(p, n)$ & 15 & $2.55 \mathrm{E}+07$ & $3.15 \mathrm{E}+02$ \\
\hline
\end{tabular}

Table 1. Dose rates due to various isotopes from the unshielded beam stop.

As shown in Table 1 dose rate is dominated by the neutron production from the $(\mathrm{p}, \mathrm{n})$ reaction on titanium isotope - Ti49. Thus we assume the entire source is coming from isotropically emitted $1.5 \mathrm{MeV}$ neutrons. This choice was made on the basis of TENDL-2012 [3] for Ti49.

\subsection{Activation analyses}

The standard way of SNS activation analyses, using the activation script [4], assumes that analyses are driven by high-energy proton beams. However, this procedure is not suitable for assessing problems driven by low-energy protons, which depend largely on correct treatment of threshold reactions. For this reason a custom procedure for analyzes was developed, covering the proton-induced and neutron-induced activities. 
The larger part of the beam stop material activation is proton-induced, the calculation of which, is described first. Due to the relatively low energy of the source protons of $2.5 \mathrm{MeV}$ and the slowing down of protons within micrometers of track length, the probability of the $(p, x)$ reaction, where $x$ is any out-coming particle, is low, and there are no activation cross section libraries coming with MCNPX transport code that would allow a direct isotope production analysis. In order to calculate isotope production rates, isotope production cross section for the stables isotopes in the beam stop were extracted from TENDL-2014 nuclear data library [5]. Macroscopic cross sections are obtained by multiplying cross sections with atomic density of the isotope in the material. The obtained macroscopic cross sections have been transformed to group macroscopic cross sections in the group structure shown in Table 2 assuming a flat proton flux energy distribution.

Proton fluxes in this energy group structure were calculated using MCNPX. The full proton beam, described above, was used as a source. Due to the low incoming proton energy, proton fluxes only in the inner cell of the beam stop were found to be nonzero. Fluxes for this cell were extracted.

Then macroscopic cross sections were folded with proton fluxes, in order to obtain isotopes production rates that were collected in the file "splprods" for consequent transmutation analyses by CINDER' 90 code [6].

Table 2. Group structure.

\begin{tabular}{|c|c|}
\hline $\begin{array}{c}\text { Lower energy } \\
\text { boundary, MeV }\end{array}$ & $\begin{array}{c}\text { Upper energy } \\
\text { boundary, MeV }\end{array}$ \\
\hline 1 & 1.2 \\
\hline 1.2 & 1.5 \\
\hline 1.5 & 1.75 \\
\hline 1.75 & 2 \\
\hline 2 & 2.2 \\
\hline 2.2 & 2.5 \\
\hline
\end{tabular}

Neutrons originating from the proton reactions in the beam stop contribute a small fraction to the activity. Their source strength was assessed for the dose rate analyzes analyses above and applied in a MCNPX transport calculation, which provided neutron fluxes in the beam stop geometry (cells).

The cell based activation analysis using the standardized activation script considered the neutron part by feeding the neutron fluxes into the CINDER90 code (the folding of neutron fluxes and neutron activation cross section is performed by CINDER90 internally) and by feeding the proton part as isotope production rates through the "splprods" file.

\section{Results}

Dose rate and activation analyses were performed for the facility operation at full beam power in order to develop proper shielding around the beam stop and to predict isotope inventory of the TZM beam stop in the end of the life time for decommissioning purposes The accident case to estimate dose rate around the facility fence in case of beam mis-steering was considered as well.

\subsection{Normal beam operation}

According to the provided drawing of the BTF beam stop, shielding analyses of the dose rates were performed and suggestions for additional shielding in order to reduce dose rates to below $0.25 \mathrm{mrem} / \mathrm{h}$ were made.

The first set of analyses was performed with no shielding near the penetrations, just general shielding around the beam stop. A second set of analyses was performed to reduce the dose rate around the beam stop below $0.25 \mathrm{mrem} / \mathrm{h}$ at $30 \mathrm{~cm}$ distance from the surfaces. Shielding was added under the beam stop, around the beam pipe and on the upstream surface of beam stop shielding. The dose rate maps in the beam stop vicinity with shielding only around the beam stop, and with added shielding as on Figure 1 (extended shielding) are shown in vertical cross section on Figure 2 and 3 respectively.

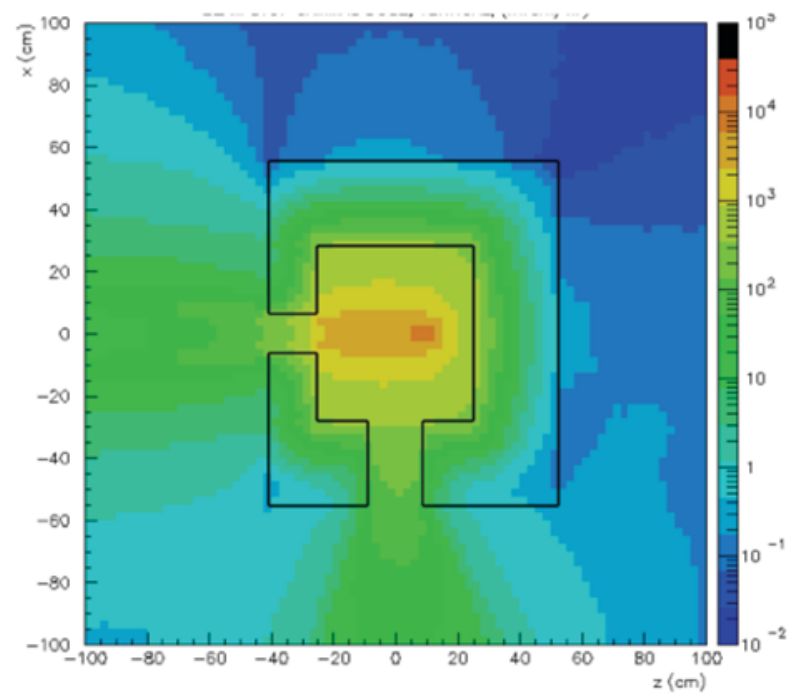

Figure 3. Total dose rate map in the vicinity of the beam stop with the general shielding, vertical cross section, $\mathrm{mrem} / \mathrm{h}$.

Table 3 shows dose rates at key locations at $30 \mathrm{~cm}$ distance from the surfaces, locations for the dose rate on the floor are directly on the floor surface. 


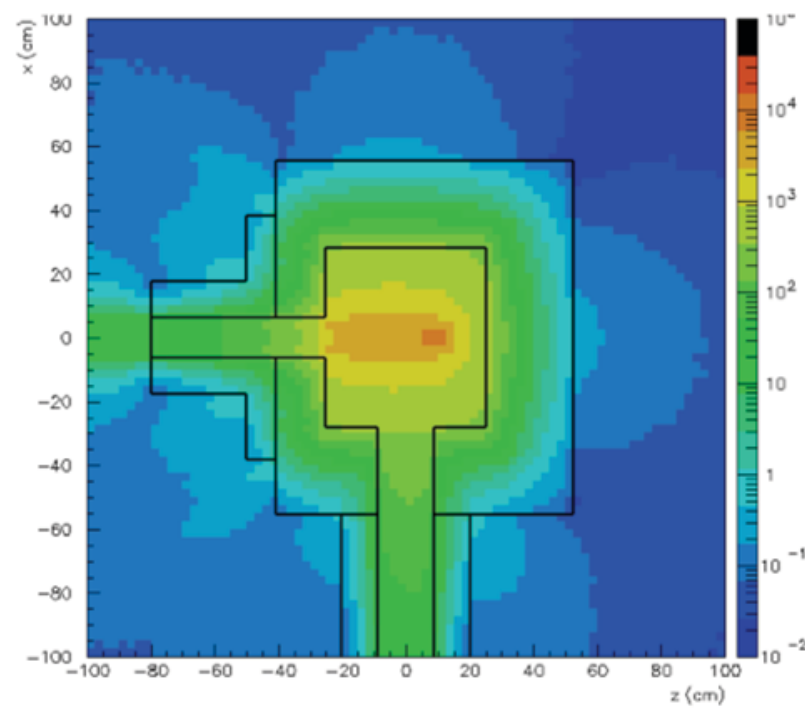

Figure 4. Total dose rate map in the vicinity of the beam stop with the added shielding, vertical cross section, $\mathrm{mrem} / \mathrm{h}$.

Table 3. Neutron dose rates during at key locations at 30 $\mathrm{cm}$ distance from the surfaces

\begin{tabular}{|c|c|c|}
\hline Location & $\begin{array}{c}\text { Shielding } \\
\text { only around } \\
\text { the beam stop }\end{array}$ & $\begin{array}{c}\text { Extended } \\
\text { shielding }\end{array}$ \\
\hline Above the shielding & 0.1 & 0.1 \\
\hline Behind the shielding & 0.14 & 0.14 \\
\hline Aside the shielding & 0.1 & 0.1 \\
\hline Upfront shielding & 3.3 & 0.11 \\
\hline Beam pipe & 4.3 & 0.12 \\
\hline $\begin{array}{c}\text { On the floor under } \\
\text { the beam stop }\end{array}$ & 30 & 30 \\
\hline $\begin{array}{c}\text { On the floor at the } \\
\text { downstream edge of } \\
\text { the beam stop } \\
\text { shielding }\end{array}$ & 0.8 & 0.08 \\
\hline
\end{tabular}

\subsection{Accident case}

The accident scenario, when beam is mis-steered, was analyzed as well. The possible accidents are when the proton beam will intercept the stainless steel beam pipe or the copper structures. Hand estimates of secondary neutrons and gammas yield resulting from protons reactions with steel and copper were performed and then converted to the dose rates as described in the methods section.

According to the analyses the expected dose rate is $7600 \mathrm{mrem} / \mathrm{h}$ and $13700 \mathrm{mrem} / \mathrm{h}$ neutron dose at $30 \mathrm{~cm}$ from the accident point on stainless steel and on copper, respectively. The expected gamma dose rate is about two orders of magnitude less than neutron dose rate.

The BTF facility is located inside a fence enclosing the radiation area. In order to predict the dose rates at the different places near the fence for unshielded section of the facility, hand estimates, based $1 / \mathrm{R}^{2}$ attenuation were used. Table 4 shows dose rate at the different distances from beam interception point during the accident on stainless steel, when $2.5 \mathrm{MeV}$ proton beam is missteered and hits the unshielded beam pipe. For accident on the copper the dose rates will be 1.8 times higher.

Table 4. Neutron dose rates during the accident near the radiation fence.

\begin{tabular}{|c|c|}
\hline Distance, $\mathbf{c m}$ & Dose rate, $\mathbf{~ m r e m} / \mathbf{h}$ \\
\hline 30 & 7600 \\
\hline 100 & 684 \\
\hline 232 & 1 \\
\hline 300 & 72 \\
\hline 400 & 43 \\
\hline 600 & 19 \\
\hline 700 & 14 \\
\hline 1000 & 6.9 \\
\hline
\end{tabular}

\subsection{Activation analyzes}

Isotope inventory for TZM beam stop after 100 hours of operation spread over 10 years was analyzed for decay times for up to 10 years. In order to make simulation closer to the real scenario it was assumed that there is a proton beam on beam stop for 25 hours at an experiment campaign and 730 days of break between campaigns for four campaigns. The nuclide of highest long-term activation (up to 10 years) is V49, and those contributing most at short decay times (up to 1 day) are Tc95 and Tc96. Activity in Ci in both TZM beam stop and cooling water during 10 years decay time followed 10 years of operation is shown in Figure 5. Isotope inventory was extracted from transmutation code output and results were compared to DOE CAT-3 threshold [7]. Hazard values, ratio of isotope activity over the threshold values, were estimated for each isotope; the summed up hazard values over all isotopes are under $3 \mathrm{e}-08$ even for 1 minute after the beam termination.

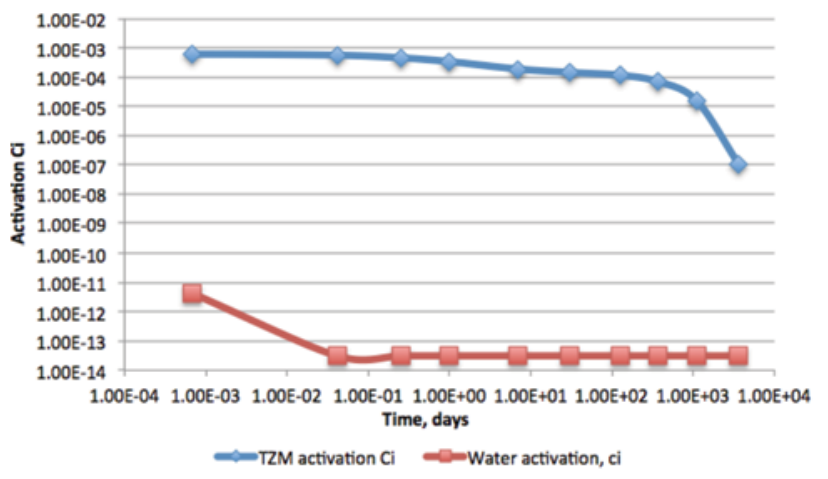

Figure 5. Activity in $\mathrm{Ci}$ in both TZM beam stop and cooling water during 10 years decay time followed 10 years of operation.

\section{Conclusions}

Shielding and activation analyses are performed to address radiation protection questions for BTF Dose rates near the beam stop were analysed and proper 
shielding was suggested. Accident cases, when beam was mis-steered and hits steel or copper, were analysed.

Activation analyses for beam stop material and cooling water were performed

\section{References}

1. C D. Pellowitz, ed., "MCNPX User's Manual, Version 2.6.0," LA-CP-07-1473, Los Alamos National Laboratory, Los Alamos, New Mexico (April 2008). (also see http://mcnpx.lanl.gov).

2. Experimental Nuclear Reaction Data (EXFOR) Database Version of May 17, 2007. See http://www.nndc.bnl.gov/exfor/exfor.htm.

3. TENDL-2012 TALYS-based evaluated nuclear data library, 2012, see http://www.talys.eu/tendl-2014/

4. F. X. Gallmeier and M. Wohlmuther, Activation Script Version 1.0 User Guide, ORNL-TM2008/031, Oak Ridge National Laboratory, August 2008.

5. By A.J. Koning ${ }^{1}$, D. Rochman ${ }^{1}$, S.C van der Marck ${ }^{1}$,

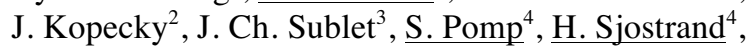

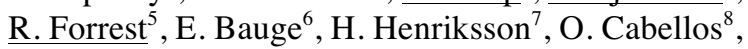
S. Goriely $^{9}$, J. Leppanen ${ }^{10}$, H. Leeb ${ }^{11}$, A. Plompen ${ }^{12}$, R. Mills ${ }^{13}$ and S. Hilaire ${ }^{6}$, TENDL-2014: TALYSbased evaluated nuclear data library, ${ }^{1} \mathrm{NRG}^{2}$ JUKO Research, ${ }^{3}$ CCFE, ${ }^{4}$ Uppsala Univ., ${ }^{5}$ IAEA, ${ }^{6} \mathrm{CEA},{ }^{7}$ Vattenfall, ${ }^{8} \mathrm{NEA},{ }^{9} \mathrm{ULB},{ }^{10} \mathrm{VTT},{ }^{11} \mathrm{ATI}$, ${ }^{12}$ IRMM, $\quad{ }^{13} \mathrm{NNL}$. See (ftp://ftp.nrg.eu/pub/www/talys/tendl2014/tendl2014 .html), December 2014

6. W. B. Wilson, S.T. Cowell, T. R. England, A.C.Hayes, P. Möller, A Manual for Cinder'90 Version 07.4, LA-UR-07-8412, Los Alamos National Laboratory, Los Alamos, (2007).

7. DOE STANDARD, HAZARD CATEGORIZATION AND ACCIDENT ANALYSIS TECHNIQUES FOR COMPLIANCE WITH DOE ORDER 5480.23, NUCLEAR SAFETY ANALYSIS REPORTS, DOE-STD-102792, December 1992. 